\title{
Designing Online Collaborative Tasks for Language Learning
}

\author{
Xuelian Lei \\ Jiangxi Institute of Education, Nanchang, Jiangxi, China \\ Email: thundersnow@126.com
}

\begin{abstract}
Designing online collaborative tasks for language learning is a challenge. This article aims to provide guidelines for creating effective online collaborative tasks. First, a definition of an online collaborative task is proposed. Then it comes to discuss the ways task design may relate to theories of learning, practical guidelines and examples for constructing collaborative tasks. The article concludes with suggestions for future language task research and design.
\end{abstract}

Index Terms - designing, online collaborative tasks, language learning

\section{INTRODUCTION}

Chapelle (2001, P.2) poses the challenge that 'anyone concerned with second language teaching and learning in the 21 st century needs to grasp the nature of the unique technology-mediated tasks learners can engage in for language acquisition' ... A key part of Chapelle's challenge is to think of ways to construct tasks so that we can make effective use of these vast computer networks. These tasks remain central, though earlier attempts to migrate classroom-based tasks to online environments have not always been successful. Clearly, as we make greater use of networked environments, we need to gain experience in developing and using technology-mediated tasks. With collaborative learning in mind, we will have an overview of the way tasks align with educational theory and a brief sketch of social constructivism.

\section{LINKING TASKS WITH EDUCATIONAL THEORY}

The role of a task in online learning shifts, depending on its intended use and underlying pedagogical theory. For example, if a teacher believes that Web surfing is a productive learning activity, her tasks would have few explicit directions or outcomes. So she would defend her view of learning as a 'discovery' of new information based on individual need (Bruner, 1985). By contrast, a teacher who advocated sequenced instruction would design each task so that it would make an incremental contribution to a larger set of carefully constructed modules. This teacher would defend his task design on a 'structured' approach to teaching.

\section{Defining Collaborative L2 Pedagogical Tasks}

For our present purposes, a focus on these authors' 'pragmatic/ pedagogical' definition of a learning task is useful:

A task is an activity, influenced by learner choice, and susceptible to learner reinterpretation, which requires learners to use language, with an emphasis on meaning, to attain an objective. (Bygate, Skehan \& Swain, 2001)

We can rework their clearly set definition to fit our own networked computer environment context, and underpin it by highlighting social constructivist principles as follows:

A collaborative online task is a loosely directed activity, shaped and interpreted by members of a learning team, which requires learners to communicate through the use of networked computers, with an emphasis on the production and integration of authentic online resources, to achieve a milestone within a larger project that itself is extensible to other contexts.

To serve as a basis for collaborative projects we can, therefore, build upon the Bygate, Skehan and Swain (2001) definition by emphasizing the 'loosely directed' nature of constructivist tasks. But how loose should the initial design parameters of such tasks be? In general, however, Jonassen and Land (2000) advise that activities designed for online learning environments be 'scaffolded' in achievable steps. Here, the influence of elaboration theory (Ausubel, 1963; Reigeluth, 1987) within a collaborative setting provides guidance for inexperienced learners.

Accordingly, they see that tasks designed for authentic purposes need to: a) relate to real-world activities; b) avoid predetermined outcomes; and c) vary in levels of complexity. In a further extension, Chapelle (2001, P.55) discusses criteria for CALL task appropriateness. Here authenticity is integrated within a cluster of other necessary factors that include language learning potential, learner fit, meaning focus, positive impact and practicality.

\section{CONSTRUCTIVIST PRINCIPLES}


The foundation of much online collaborative learning rests in the principles of social constructivism.

Social constructivists promote close ties between authentic activities, collaborative learning, a variety of materials, the student ownership of outcomes and critical reflection. According to Driscoll (2000), the five key principles of this learning theory are as follows:

\section{A. Integrating Authentic Activity within a Complex Learning Environment}

Students readily discern what will and will not be useful to them. They know, for example, that the Internet will be part of their lives. The use of real Internet resources heightens a sense of authenticity and provides motivation.

\section{B. Emphasizing Social Negotiation as Integral to Learning}

Placing a collaborative task at the core of a class focuses student attention on group dynamics and interpersonal communication; task completion hinges on students' collaboration. Audience awareness, a key part of effective communication skills, is also developed at several levels through interpersonal, group, institutional and, potentially, global interactions.

\section{Combining Content with Multiple Modes of Representation}

Collaborative tasks, by their very nature, contain a juxtaposition of ideas and information. Working through a range of electronic resources with colleagues helps students to gain experience in a variety of modes: spoken, written, individual, group and technologically mediated.

\section{Relating Instruction to Student Needs}

Well-designed collaborative tasks allow scope for students to shape outcomes; their ownership of the work is made clear from the beginning. As a need arises in relation to a task - and this includes conflicts within the group - we can provide guidance and some perspective.

\section{E. Reflecting on Practice}

Thinking about what went right, what went wrong and how it can be improved next time is a powerful way to deepen understanding. Done well, reflection encourages a critical perspective and transferability of learning to other contexts.

\section{F. Putting Theory into Practice}

The use of clear design procedures, reproducible templates and model sites can assist task writers. The comprehensive WebQuest site (webquest. sdsu. edu) for native speakers provides solid guidelines for task design (Dodge, 2002) that can be readily adopted for second language programs. Consider the following six steps to writing online collaborative tasks as shown in Table 1:

TABLE 1:

GUIDELINES FOR ONLINE COLLABORATIVE TASK DESIGN

\begin{tabular}{|c|c|}
\hline Task component & purpose \\
\hline Introduction & Prepare and motivate learner interest in the area \\
\hline Setting objective & Describe clearly and simply what you expect learners to achieve \\
\hline Steps and process & Explain the steps that learners should go through to achieve the objective \\
\hline Resources & Provide a list of authentic online resources that learners can use to achieve the objective \\
\hline Evaluation & $\begin{array}{l}\text { Tell learners how to check their work through the provision of model responses that relate to specific goal } \\
\text { within an established curriculum. }\end{array}$ \\
\hline Reflection and Extension & Encourage Learners to think about what has been learned and how to apply that learning to different contexts. \\
\hline
\end{tabular}

(Adapted from Corbel, Gruba, and Enright, 2002)

Online collaborative tasks can be situated within the context of a larger project. In an ideal situation, each project generated in a single classroom contributes to an overall theme, and each task within a project resonates in some way with that theme. Ideal tasks involve every member of the class, both within project teams and across the class as a whole, as expertise is shared among the entire group. Through this sharing, individual students can see and reflect upon the ways in which their contribution relates both to the team and to the wider organization. Effective collaborative tasks are appropriate, extensible and encourage reflection.

Although the ultimate aim of the example task is to produce a collaborative report, the task is constrained so that an individual only writes a section of the report, since our students are not always able to collaborate. However, by placing the task within a larger project, it can be extended and related back to an overall theme. In this case, each team in the class could examine 'entertainment options' across the city, and then debate the merits of each reported venue. If the resources are available, the task could also act as a catalyst for students to create their own online materials (for example, a team could write a guide for international visitors to a tourist attraction). Any texts they created could potentially be useful to readers who wanted information on the presented topic.

Finally, because 'reflection' and 'extension' are key tenets of social constructivist approaches to learning, a key characteristic of collaborative tasks is to ensure they can be used to stimulate further learning. Task designs, therefore, need to be concluded in such a way that they encourage students both to think about what they have learnt and how to apply that learning in other contexts. 


\section{FURTHER DEVELOPMENT}

One way to meet Chapelle's (2001) challenge regarding technologically mediated tasks lies in our collective attempts to define them, write them and try them out with our own students. As we move from theory to practice through networked computer environments, we need to be acutely aware of how task design can be underpinned by sound pedagogical approaches. Research can be focused on four key areas: 1) understanding actual student use of technologically mediated tasks, for example, how they use such tasks in both online and offline contexts; 2) the use of collaborative tasks within groups; 3 ) collaborative task usage across groups; and 4) the role of collaborative tasks in assessment.

As our field begins to consider the need to develop 'multiliteracies' (Cope \& Kalantzis, 2000) - so that our students can cope with a greater variety of text types, intertextual references and modalities - we need to expand our list of factors that may influence the use and definitions of online tasks. We should also consider making explicit statements regarding mode of presentation in task design. For example, 'video-mediated' tasks need to be clearly differentiated from 'audio-mediated' tasks when we set out to design online listening activities. We will need a stronger understanding of the attributes of a multimedia production if we are to exploit it effectively (Chun and Plass, 1997).

Another way to meet the challenge of understanding effective technologically mediated tasks is to find ways to better teach their design and use. We need to create purposeful training modules that address the unique demands of online collaborative environments. Staff development materials that foster effective online task design for use both in teaching and action research already exist (Corbel, 2001). Beyond that, however, teachers must experience for themselves 'learning how to learn' in networked teams, and come to consider using social constructive approaches to teaching rather than remaining somewhat suspicious of them (Debski \& Gruba, 1999).

By using some structured guidelines and inspiration from existing WebQuest sites, second language instructors can construct their own materials, try them with colleagues and meet the challenges of designing technologically mediated tasks.

\section{REFERENCES}

[1] Bachman, L. F., \& Palmer, A. S. (1996). Language testing in practice. Oxford: Oxford University Press.

[2] Bruner, J. (1985). Models of the learner. Educational Researcher, June, p. 5-8.

[3] Bygate, P. Skehan \& M. Swain (Eds.). Researching pedagogic tasks: Second language learning, teaching and testing, p. 1-20. Harlow, UK: Pearson.

[4] Chapelle, C. A. (1999). Theory and research: Investigation of 'authentic' language learning tasks. In J. Egbert \& E. H. Smith (Eds.), CALL environments: Research, practice and critical issues, p. 101-115. Alexandria, VA: TESOL.

[5] Chapelle, C. A. (2001). Computer applications in second language acquisition. Cambridge: Cambridge University Press.

[6] Chun, D. M., \& Plass, J. L. (1997). Research on text comprehension in multimedia environments. Language Learning \& Technology, 1, P. 60-81.

[7] Cope, B., \& Kalantzis, M. (Eds.). (2000). Multiliteracies: Literacy learning and the design of social futures. South Yarra, Vic: Macmillan.

[8] Corbel, C., Gruba, P., \& Enright, H. (2002). Taking the Web to task. Sydney: NCELTR.

[9] Debski, R. (Ed.). (2000). Project-oriented CALL: Implementation and evaluation (Special Edition). Computer Assisted Language Learning, 13, Issues 4-5.

[10] Debski, R., \& Gruba, P. (1999). A qualitative survey of tertiary instructor attitudes towards project-based CALL. Computer Assisted Language Learning, 12(3), p. 219-239.

[11] Dodge, B. (2002). Webquest taskonomy: A taxonomy of tasks. Retrieved July 30, 2004, from http://webquest.sdsu.edu/taskonomy.html

[12] Driscoll, M. (2000). Psychology of learning for instruction (2nd ed.). Boston: Allyn \& Bacon.

[13] Johnson, K. (2000). What task designers do. Language Teaching Research, 43, p. 301-321.

[14] Jonassen, D., \& Land, S. (2000). Theoretical foundations of learning environments. Mahwah, NJ: Lawrence Erlbaum Associates.

[15] Kern, R., \& Warschauer, M. (2000). Introduction: Theory and practice of networked-based language teaching. In M. Warschauer \& R. Kern (Eds.), Network-based language teaching: Concepts and practice, p. 1-19. Cambridge: Cambridge University Press.

Xuelian Lei was born in Jiangxi, China in 1978. She received her M.A. degree in English Curriculum and Teaching Theory from Hangzhou Normal University, China in 2009.

She is currently a teacher in the Foreign Languages Department, Jiangxi Institute of Education, Nanchang, China. Her research interests include language teaching and research, linguistics, translation. 